\title{
Reactive combinatorial synthesis and characterization of a gradient Ag-Ti oxide thin film with antibacterial properties
}

\author{
Erik Unosson $^{\mathrm{a}^{*}}$, Daniel Rodriguez ${ }^{\mathrm{b}, \mathrm{c}}$, Ken Welch $^{\mathrm{d}}$, Håkan Engqvist $^{\text {a }}$ \\ ${ }^{a}$ Division of Applied Materials Science, Department of Engineering Sciences, The Ångström \\ Laboratory, Uppsala University, Box 534, 75121 Uppsala, Sweden \\ ${ }^{\mathrm{b}}$ Biomaterials, Biomechanics and Tissue Engineering Group, Department of Materials Science and \\ Metallurgical Engineering, Technical University of Catalonia, Avenida Diagonal 647, E08028 \\ Barcelona, Spain \\ ${ }^{c}$ Biomedical Research Networking Centre in Bioengineering, Biomaterials and Nanomedicine \\ (CIBER-BBN), Spain \\ ${ }^{\mathrm{d}}$ Division of Nanotechnology and Functional Materials, Department of Engineering Sciences, The \\ Ångström Laboratory, Uppsala University, Box 534, 75121 Uppsala, Sweden \\ *Correspondence to: Erik Unosson \\ e-mail: erik.unosson@angstrom.uu.se \\ Tel: +4618 4717946
}




\section{Abstract}

Growing demand for orthopedic and dental implants has spurred researchers to develop multifunctional coatings, combining tissue integration with antibacterial features. A possible strategy to endow titanium (Ti) with antibacterial properties is by incorporating silver $(\mathrm{Ag})$, but designing a structure with adequate $\mathrm{Ag}^{+}$release while maintaining biocompatibility has been shown difficult. To further explore the composition-structure-property relationships between $\mathrm{Ag}$ and $\mathrm{Ti}$, and its effects against bacteria, this study utilized a combinatorial approach to manufacture and test a single sample containing a binary Ag-Ti oxide gradient. The sample, sputter deposited in a reactive $\left(\mathrm{O}_{2}\right)$ environment using a custom built combinatorial physical vapor deposition (PVD) system, was shown to be effective against Staphylococcus aureus with viability reductions ranging from 17 to above $99 \%$, depending on amount of $\mathrm{Ag}^{+}$released from its different parts. The $\mathrm{Ag}$ content along the gradient ranged from 35 to $62 \mathrm{wt} \%$, but it was found that structural properties such as varied porosity and degree of crystallinity, rather than amount of incorporated $\mathrm{Ag}$ governed the $\mathrm{Ag}^{+}$ release and resulting antibacterial activity. The coating also demonstrated in vitro apatite forming abilities, where structural variety along the sample was shown to alter the hydrophilic behavior, with degree of hydroxyapatite (HA) deposition varying accordingly. By means of combinatorial synthesis, a single gradient sample was able to display intricate compositional and structural features affecting its biological response, which would otherwise require a series of coatings. The current findings suggest that future implant coatings incorporating $\mathrm{Ag}$ as an antibacterial agent could be structurally enhanced to better suit clinical requirements. 
Keywords: Combinatorial materials science; physical vapor deposition; antibacterial; silver; titanium. 


\section{Introduction}

The conventional, one sample at a time, trial-and-error synthesis of new materials or coatings can be a tedious process. By applying a combinatorial approach instead, multiple compositions and structures can be deposited onto a single substrate simultaneously, which facilitates rapid screening of composition-structure-property relationships for specific functions, and helps to build new materials libraries. The aim of the combinatorial approach is thus to accelerate the discovery of new materials, as well as speed up optimization of known ones, by combining sophisticated synthesis methods with high-throughput property screening. This concept was adopted by electronic materials researchers in the 1960s [1,2] and further developed by the pharmaceutical industry through the 1990s for fast-tracked drug discovery $[3,4]$. In biomaterials research, the technique has been increasingly applied through automated fabrication of polymeric microarrays for specific cell response evaluation, as well as screening of synthetic substrates for stem cell culture [5,6]. For combinatorial thin films with inorganic composition-gradients, however, most research and development has been focused on materials for electronic, optical, magnetic and energy-related applications $[7,8]$, and corresponding investigations for biomaterials applications are scarce. Although thin film coatings for biomedical implants and devices are all the while being widely researched to improve functionality and safety, no simple solution exists to, for instance, combat or prevent implant-associated infection [9-11]. This work presents a combinatorial approach to synthesizing an inorganic composition-gradient between silver and titanium, using a custom built physical vapor deposition (PVD) system, and aims to correlate the resulting composition and structure with antibacterial properties. 
Titanium is a widely used implant material with good mechanical properties and a long track record of biocompatibility [12], largely due to a passivation layer of $\mathrm{TiO}_{2}$ that forms naturally on its surface. Silver on the other hand is intrinsically antibacterial, as silver ions $\left(\mathrm{Ag}^{+}\right)$have been shown to harm bacteria by causing DNA alterations, leading to lost replication ability, and by inactivating bacterial proteins by binding to essential thiol groups [13]. In controlled amounts however, it presents little or no cytotoxic effects [14-16]. Incorporating silver in coatings with well-known biocompatibility and bioactivity, such as hydroxyapatite (HA) $[17,18]$ or $\mathrm{TiO}_{2}$ $[16,19,20]$, has thus been presented as a viable option to reduce surgical site infection related to orthopedic and dental implants, while still maintaining good osseointegration properties. As a non-antibiotic agent with low propensity to develop bacterial resistance, silver can also be used to reduce the spread of methicillinresistant strains $[1,2,19,21]$.

The amount of silver that should be incorporated into such structures, and in what form it is most effective is, however, still an open question. To control the ion release, focus has shifted from bulk silver to nanoscale coatings and doped solids or hydrogels, with impregnated catheters and wound dressings already in clinical use $[3,4,22,23]$. With the use of silver nanoparticles (Ag NPs) for example, a higher surface area will increase the $\mathrm{Ag}^{+}$release. $\mathrm{Ag}$ NPs can also disrupt the bacterial membrane and become internalized, inducing further DNA damage $[5,6,22,24]$. These bactericidal mechanisms are, however, still not completely understood, nor are the potential adverse effects or the fate of the Ag NPs. This study therefore aims at determining an appropriate structure and balance between silver and titanium in a solid coating by creating a continuous compositional gradient between the two, and evaluating the different parts of the coating for biomedical purposes. To the authors' 
best knowledge, this general approach to designing an antibacterial coating by combinatorial means has not been attempted before. 


\section{Materials and Methods}

\subsection{Combinatorial deposition}

The gradient Ag-Ti oxide thin film analyzed in this work was sputter deposited on a 3-inch (100) p-type silicon wafer using 3-inch diameter, pure (99.99\%) Ag and Ti targets (Testbourne Ltd., Basingstoke, UK). The two targets were placed opposing each other in a custom built, off-axis PVD system (equipped with four equally spaced sputter sources), mounted at a $45^{\circ}$ angle against the manipulator holding the substrate, as depicted in Fig. 1. This binary system of opposing targets allows for the creation of thin film coatings with a continuous compositional gradient across the substrate, containing Ag- and Ti-rich ends close to each respective target.

Prior to deposition, the substrate was degassed for 20 min at $650^{\circ} \mathrm{C}$ and then allowed to cool to room temperature, at which the deposition was made. After reaching a base pressure below $10^{-8}$ Torr, working $(\mathrm{Ar})$ and reactive $\left(\mathrm{O}_{2}\right)$ gases were back-filled into the chamber with flow rates adjusted to 10 and $1 \mathrm{sccm}$, respectively, using separate mass flow controllers. The working pressure for deposition was adjusted to 2 mTorr using a throttle valve regulator between the chamber and turbo pump. Direct current (DC) power supplies connected to water-cooled magnetrons were adjusted to $120 \mathrm{~W}$ for the Ti target and $10 \mathrm{~W}$ for the Ag target. After presputtering the targets for $10 \mathrm{~min}$ to remove oxides and contaminants, both target shutters were opened for concurrent, combinatorial deposition during $60 \mathrm{~min}$.

\subsection{Surface characterization}

Structural information about the thin film was obtained by grazing incidence X-ray diffraction (GI-XRD) using a X'Pert PRO MRD system (Philips/PANalytical, Almelo, Netherlands) in continuous mode, scanning $2 \theta$ from $10^{\circ}$ to $90^{\circ}$ with a step 
size of $0.04^{\circ}$ and the incident beam set to $1^{\circ}$. Surface imaging, cross-sectional analysis and elemental analysis were made using scanning electron microscopy (SEM), focused ion beam (FIB) and energy dispersive x-ray spectroscopy (EDS) in a crossbeam Neon 40 workstation (Zeiss, Oberkochen, Germany). Complementary SEM and EDS was also done in a LEO 1550 (Zeiss). Wettability along the compositional gradient was determined by the sessile drop method in a video-based optical contact angle measuring system (OCA 15+, DataPhysics, Filderstadt, Germany), using Milli-Q water as the probe liquid and taking measurements at $6 \mathrm{~mm}$ intervals along the sample. Prior to contact angle measurements, the surface was sonicated in ethanol and distilled water for $1 \mathrm{~min}$ each to remove adhered contaminants. Potential superhydrophilic properties related to $\mathrm{TiO}_{2}$ photocatalysis were investigated by illuminating the surface with UV light $(\lambda=365 \pm 10 \mathrm{~nm})$ for 15 min, followed by repeating the contact angle measurements. The UV light source was calibrated using a light meter (UV-340, Lutron, Taiwan) and set to deliver an intensity of $2 \mathrm{~mW} / \mathrm{cm}^{2}$ at the surface. Surface roughness of the coating was evaluated in three areas along the gradient using a WYKO NT1100 optical profiler (Veeco Instruments Inc., CA, USA) in vertical shift interferometry mode.

\subsection{In vitro antibacterial properties}

Antibacterial activity along the gradient thin film was tested against Staphylococcus aureus (CCUG 15915) in a bacterial adhesion test, quantified by counting colony-forming units (CFUs). S. aureus cells were inoculated in brain heart infusion (BHI) broth (Scharlau, Barcelona, Spain) and overnight cultured at $37^{\circ} \mathrm{C}$. The culture was then diluted in sterile $\mathrm{BHI}$ to obtain an $\mathrm{OD}_{600}$ value of 0.2 using a 
UV-Vis spectrophotometer (UVmini-1240, Shimadzu, Kyoto, Japan), which corresponds to approximately $10^{8} \mathrm{CFU} / \mathrm{mL}$. To better distinguish antibacterial effects along the compositional gradient, $1 \times 1 \mathrm{~cm}^{2}$ samples were cut in duplicates from $\mathrm{Ag}$ rich, center and Ti-rich parts of the coated wafer. Samples cut in the same dimensions from an uncoated silicon wafer were tested in parallel to serve as negative control. A repeated test was performed using a pure Ti coating as negative control. Confined in a laminar flow hood, samples were sterilized for $10 \mathrm{~min}$ in ethanol and washed twice for 10 min in Milli-Q water in individual wells of a 24-well plate. After allowing any remaining liquid to evaporate, $10 \mu \mathrm{L}$ of the $S$. aureus suspension was pipetted and dispersed evenly across each surface, and the entity was incubated under lid at $37^{\circ} \mathrm{C}$ for $2 \mathrm{~h}$. Neighboring wells were filled with Milli-Q water to control humidity and vapor pressure, ensuring that evaporation of the suspension liquid was kept to a minimum. Adding a small amount of bacteria to the active surface, rather than submerging the entire sample in culture, allows for a closer control of bacterial adhesion and aids in evaluating the bactericidal action [25]. After incubation, $1 \mathrm{~mL}$ phosphate buffered saline (PBS) was added and extracted to remove non-adherent bacteria, and $1 \mathrm{~mL}$ fresh PBS was added to each well. The plate containing the samples was then sonicated for $30 \mathrm{~s}$ to detach and suspend the adhered bacteria, which has previously been shown an effective method [26,27]. Ten-fold, serial dilutions were then plated in duplicates on BHI agar plates and incubated overnight at $37{ }^{\circ} \mathrm{C}$ before counting viable colonies. Results from the tests were pooled, and the count was expressed as survival rate (\%) compared to the negative control. Statistically significant differences $(p<0.05)$ in CFU count were identified by oneway ANOVA followed by a post-hoc Sheffe's multiple comparisons test using IBM SPSS v19.0 statistics software. 


\subsection{Silver ion release and in vitro apatite formation}

A combined test was conducted to analyze $\mathrm{Ag}^{+}$release from the gradient coating, and the coatings in vitro apatite forming abilities. Samples of $1 \mathrm{~cm}^{2}$ were cut from Ag-rich and Ti-rich ends of the coated wafer and immersed in $35 \mathrm{~mL}$ Dulbecco's phosphate buffered saline with $\mathrm{MgCl}_{2}$ and $\mathrm{CaCl}_{2}$ (D-PBS, Sigma-Aldrich, St. Louis, MO, USA), having an ion concentration similar to that of human blood plasma (Table 1), thus serving as a simulated body fluid (SBF). This method has been shown to function well as a biomimetic HA deposition technique on bioactive substrates, but can also serve as an in vitro bioactivity indicator in evaluating the degree of apatite formation [28-30]. The D-PBS solutions and samples were held at $37{ }^{\circ} \mathrm{C}$ and kept on a gently rocking platform, and the D-PBS was replenished after 1, 2, and 3 days to continually provide ions for apatite deposition. The solutions retrieved after 1, 2, 3 and 7 days were subsequently analyzed by inductively coupled plasma - atomic emission spectroscopy (ICP-AES, Spectro Ciros CCD, Kleve, Germany) to obtain silver ion release profiles from opposite ends of the compositional gradient, and the in vitro apatite formation was evaluated by imaging with SEM (LEO 1550, Zeiss) and GI-XRD analysis (Siemens D5000). The GI-XRD analysis was performed on precipitated species, which were gently removed from the surfaces and fixated on an amorphous substrate. Analysis of in vitro apatite formation was conducted on samples extracted from the D-PBS solutions after 3 and 7 days. 


\section{Results}

\subsection{Gradient thin film characteristics}

GI-XRD patterns obtained from opposite ends of the gradient film are shown in Fig. 2, and peaks representing metallic silver were dominant at both ends. Broad peaks attributable to $\mathrm{TiO}_{2}$ (rutile) were visible at the Ti-side.

In Fig. 3, SEM images of the Ag-side show the morphology and cross-section structure of the coating, which was approximately $600 \mathrm{~nm}$ thick. Irregular clusters of particles and grains, ranging in size from $20 \mathrm{~nm}$ to $1 \mu \mathrm{m}$ made up the surface. Voids in the structure were apparent from the cross-section analysis (Fig. 3c-d), where also electron dense regions (appearing brighter) indicated enrichment in silver. At the center of the gradient, imaged in Fig. 4a, silver crystals (as verified by EDS) were seen to emerge from protruding clusters. On the Ti-side, shown in Fig. 4b, silver was mainly present as Ag NPs, ranging in size from 20 to $200 \mathrm{~nm}$. Cross-sectional images of the areas are shown in Fig. 4c-d, taken by sectioning of the wafer. A porous structure filled with silver crystals and silver rich grains was found at the center, whereas a thinner and denser columnar structure containing Ag NPs was found on the Ti-side. EDS data obtained from the Ag-side, center and Ti-side are shown in Fig. 5, which revealed that the compositional gradient on the sample ranged from nearly $62 \mathrm{wt} \% \mathrm{Ag}$ and $21 \mathrm{wt} \% \mathrm{Ti}$ on the Ag-side, to an even 35wt\% Ag and 35wt\% Ti on the Ti-side, with the remaining main constituent being oxygen. In atomic terms, this translates to a gradient range of 27-11 at\% $\mathrm{Ag}$, and a corresponding 20-27 at\% $\mathrm{Ti}$.

Contact angle measurements, seen in Fig. 6, showed that wettability of the surface varied along the gradient. The contact angle increased from $9^{\circ}$ at the Ag-side to $49^{\circ}$ at the Ti-side. Illuminating the sample with UV light caused a general decrease in contact angle across the surface. Parameters $R_{\mathrm{a}}$ (average roughness) and $R_{\mathrm{q}}$ (root 
mean square roughness) are shown in Fig. 7, which demonstrated that the surface roughness decreased significantly towards the denser Ti-side.

\subsection{In vitro antibacterial properties}

The antibacterial activity of the coating was tested against $S$. aureus at three positions along the Ag-Ti oxide gradient, and compared to a negative control surface. Analysis of the number of viable bacteria after $2 \mathrm{~h}$ contact with the samples showed a clear reduction in CFUs along the gradient with increasing Ag content (Fig. 8). Compared to the control, an almost complete reduction (99.6\%) was noted at the Agside, while $58 \%$ and $17 \%$ reductions were seen at the center and Ti-side, respectively. Statistically significant differences $(p<0.05)$ were identified between all groups.

\subsection{Silver ion release and in vitro apatite formation}

Fig. 9 shows the cumulative release of silver from $1 \mathrm{~cm}^{2}$ pieces cut from the Ag- and Ti-sides of the gradient coating. After 7 days in D-PBS, a total concentration of $337 \mathrm{ppb}$ was detected in the resulting Ag-side solutions, and $47 \mathrm{ppb}$ in the Ti-side solutions. An initial burst followed by slower release characterized the Ag-side, whereas the Ti-side demonstrated a more linear, slow release throughout. Upon examining the surfaces extracted from the D-PBS solutions in SEM, an approximately $10 \mu \mathrm{m}$ thick covering layer of HA was noted on the Ag side (Fig. 10a). More scattered HA particles were seen on the Ti-side, as shown in Fig. 10b. After examining the precipitated HA in SEM, the layer was removed and fixated to an amorphous substrate for GI-XRD analysis. The presence of HA was confirmed, but also demonstrated a presence of silver (Fig. 11). Similar patterns were obtained at both ends, although with slightly higher silver intensity at the Ag-side. When re- 
analyzing the underlying coating morphology and composition, results shown in Fig. 12, the silver content on the Ag-side was found to be around $43 \mathrm{wt} \%$. The corresponding silver content on the Ti-side was approximately $35 \mathrm{wt} \%$. 


\section{Discussion}

Modern biomedical implants and devices are engineered to attract and promote a positive response from host tissue cells, e.g. osseointegration or tissue regeneration. In cases where such a "friendly" surface is instead colonized by bacteria, however, the tissue cells quickly become outnumbered and the immune system is faced with a very challenging task. This "race for the surface", first conceptualized by Gristina [7,8,31], often determines the fate of an implant. There is consequently a need for functional biomaterial surfaces that can mediate tissue cell response but also impede bacterial colonization and biofilm formation. In designing such a surface that is capable of both positive tissue response and the ability to obstruct infection, the need to administrate antibiotic drugs would also be reduced. The over use of antibiotics and increased antibiotic resistance from pathogens is considered one of the most concerning health threats of the 21 st century, and new technologies addressing the issue are desperately needed [9-11,32-34].

To develop new materials according to specific property requirements, in this case a simultaneously bioactive and antibacterial surface, an iterative trial-and-error process is often initiated to manufacture and test samples with discrete structures or compositions. This can be done by tailoring topography on the nanoscale $[12,35,36]$, by incorporating varied amounts of $\mathrm{Ag}$ in similar structures $[13,16,37,38]$, or by pursuing alternative strategies for antibacterial surfaces, thoroughly surveyed in recent reviews $[10,14-16,22]$. Although history has proven that with persistence and some chance, great discoveries can be made, the possibility of this occurring will undoubtedly be greater if more parameters can be screened in a faster and cheaper way $[17,18,39-42]$. This is, in essence, what the combinatorial approach aspires to achieve. With this in mind, the current study presents a conceptual example on how to 
manufacture and test a compositional and structural gradient between two materials with complementary biological functions on a single substrate, thereby applying the combinatorial approach to the field of biomedical implant coatings.

The gradient coating examined in this study was sputter deposited using a custom built combinatorial PVD system, with pure silver and titanium targets mounted across from each other while facing the substrate, and yielded a coating with distinctive physical, chemical and biological properties at opposing ends. By sputtering in a reactive environment $\left(\mathrm{O}_{2}\right)$, the intention was to enhance both bioactive and antibacterial properties of the coating, as formation of $\mathrm{TiO}_{2}$ facilitates osseointegration by providing chemical stability and increased wettability $[16,19,20,43]$, and incorporation of oxygen in silver is known to affect its dissolution rate [44]. The concurrent, reactive sputtering in this instance made for a compositional Ag-Ti oxide gradient with a dominant crystalline contribution from Ag. According to the GI-XRD data in Fig. 1, Ti was present as poorly crystalline rutile, amorphous oxide or possibly in tetragonal AgTi intermetallic phases, which has similar lattice features as cubic Ag. The absence of metallic Ti was likely due to its high oxygen affinity, causing it to oxidize immediately during deposition. Further, sputtering at room temperature and avoiding any subsequent crystallization heat treatment conserved the amorphous structure and any meta-stable phases. Heat treatment of the sample would likely induce crystallization and anatase or further rutile formation of available $\mathrm{TiO}_{2}$, with potential enhancement of photocatalytic properties along the gradient as a result [45]. However, raising the temperature above $75^{\circ} \mathrm{C}$ has been reported to result in considerable densification, crystallite growth and decomposition of $\mathrm{Ag}_{2} \mathrm{O}$ in nanocrystalline silver films, impeding antibacterial properties [46]. The comparably soft nature of Ag also gives it a considerably higher 
sputtering rate than $\mathrm{Ti}$, which caused $\mathrm{Ag}$ to dominate the composition of the gradient although power supplied to the Ti target was more than tenfold.

The SEM images presented in Fig. 3 and Fig. 4 demonstrated that distinct phase separation and growth of pure Ag crystals was first noted at the center of the gradient, and that the Ag contribution gradually changed from an integral part of the structure on the rather homogeneous Ag-side, to scattered nanoparticles on the Tiside. Along with a densification of the coating with decreased Ag content, this indicates an accommodation of $\mathrm{Ti}$ in the $\mathrm{Ag}$ oxide during deposition, whereas the reverse was obstructed. Immiscibility of the present phases gradually drove the nucleation and growth of Ag particles along the gradient towards the Ti-side. The compositional increase in $\mathrm{Ti}$ along the gradient was also coupled with increased oxygen content, resulting from its higher oxygen affinity than the noble Ag. The atomic Ti:O ratio, however, decreased from 1:2.65 on the Ag-side, to 1:2.3 on the Tiside, implying further that more oxygen was bound to Ag on the Ag-side than on the Ti-side. This shows that the gradient was both compositional and structural, and that the Ag contribution shifted from oxide to metallic form.

This shift was also manifested in the contact angle measurements, which showed a more hydrophilic behavior on the porous Ag-side. Formation of metallic Ag NPs along with coating densification and a smoother surface towards the Ti-side caused a net decrease in surface energy, resulting in increased contact angles. On photocatalytic $\mathrm{TiO}_{2}$ surfaces, UV light generates free radicals available to mineralize adhered contaminants (such as bacteria), but also creates a superhydrophilic surface due to increased hydroxylation [47]. This makes for an efficient, on-demand self cleaning surface, but it has also been shown that pretreatments with UV light can enhance protein adsorption, cell attachment and osteoconductivity on Ti implants, 
largely due to removal of adhered hydrocarbons [48,49]. Moreover, Ag-doped $\mathrm{TiO}_{2}$ has displayed higher photocatalytic activity and stronger antibacterial effect than regular $\mathrm{TiO}_{2}$, due to improved charge separation, making it an interesting option as a multifunctional biomedical coating [50]. Photocatalysis on $\mathrm{TiO}_{2}$ requires a crystalline structure, however, which was only detected as poorly crystalline rutile on the present coating. Hence, the photoactivity, as examined via UV-induced hydrophilicity, was limited and could not be correlated to coating composition across the sample. Nevertheless, UV illumination lowered the contact angle by as much as $11^{\circ}$ in certain areas, indicating a certain degree of photoactivity.

The structural and compositional change had a significant impact on the antibacterial properties of the coating, which was evaluated against the clinically relevant strain $S$. aureus (Fig. 8). This could be correlated to the $\mathrm{Ag}^{+}$release profiles displayed in Fig. 9, where the amount of $\mathrm{Ag}^{+}$released from the $\mathrm{Ag}$-side, compared to the Ti-side, greatly exceeded the difference in composition. This, in turn, indicated a significant change in Ag solubility along the gradient. Properties known to affect the dissolution rate of $\mathrm{Ag}$ are surface area, oxidation state, crystallinity and crystallite size [44]. A higher roughness and porosity results in significantly higher surface area, and as demonstrated by the SEM and EDS analysis of the samples after $\mathrm{Ag}^{+}$release studies (Fig. 12), both morphology and composition changed more drastically on the Ag-side. On a more hydrated surface, such as the porous and hydrophilic Ag-side, release of $\mathrm{Ag}^{+}$is generally enhanced due to greater interaction with water molecules [51]. A visibly corroded surface and considerable loss in Ag was noted on the Agside, whereas the Ti-side showed less structural and compositional change, but with most of the Ag NPs on the surface no longer present, indicating that the formed nanoparticles were loosely bound to the surface. With a respective 43 and $35 \mathrm{wt} \% \mathrm{Ag}$ 
remaining on the Ag-side and Ti-side after 7 days in D-PBS, a longer-term release is also expected. But as indicated by the $\mathrm{Ag}^{+}$release data and SEM images after release, the easily dissolved Ag was gone and the release rate declined.

As an indication of bioactivity, the in vitro apatite forming ability was tested along the gradient by submersing samples in D-PBS, which is a simple, biomimetic method used to deposit HA on bioactive substrates $[28,52]$. The test revealed a clear precipitation of HA on both Ag- and Ti-sides, although with greater coverage on the Ag-side (Fig. 10). This is hypothesized to stem from its higher surface energy, which correlates well with the contact angle measurements. It is, however, interesting to note such high degree of apatite formation on substrates with high Ag content and poor $\mathrm{TiO}_{2}$ crystallinity, which would generally result in less surface hydroxyl groups and less active sites available for apatite nucleation [53]. The presence of Ag peaks in the GI-XRD spectra of precipitated HA (Fig. 11), which were analyzed after being gently removed from the substrates, indicates that a fair amount of Ag remained in the HA rather than being released into the solution. Whether this was due to poor adhesion of surface bound Ag NPs or a dissolution-precipitation mechanism remains unclear.

Excessive doses of Ag have been reported to result in both local cytotoxic effects and systemic disease, such as agyria [54]. Therefore, a prudent approach should be applied before adding any $\mathrm{Ag}^{+}$releasing function to a biomaterial. In a study by Hardes et al. [15], however, no local or systemic side-effects were reported after placement of Ag coated megaprostheses in 20 patients, although Ag blood levels exceeded $55 \mathrm{ppb}$, and $1600 \mathrm{ppb}$ was detected in nearby tissue. As antibiotic resistance is spreading among pathogens, alternatives are sorely needed and a growing body of work is now dedicated to studying metal-based antimicrobials to treat infections [55]. The outlook is promising, but some specific mechanisms remain unclear and aspects 
of human toxicity and environmental impact require further investigations. As well, comparing $\mathrm{Ag}^{+}$release data and corresponding in vitro or in vivo response in the literature should be done cautiously, as quantification methods tend to vary among studies. The cytotoxicity and tissue cell response of novel $\mathrm{Ag}-\mathrm{TiO}_{2}$ nanotube coatings have been evaluated in recent studies, and demonstrated that a controlled release of $\mathrm{Ag}^{+}$can have sufficient antibacterial effect while maintaining, or in some instances even improving the biocompatibility $[36,38,56]$. The biological evaluation of the gradient coating presented in this work was limited to the effect against $S$. aureus bacteria, precluding the authors from drawing any conclusions regarding the mammalian cell response to the amount of $\mathrm{Ag}^{+}$released. Nevertheless, the study displays the potential of the combinatorial approach for discovery and initial screening of materials candidates for further development and biological evaluation.

The difference in Ag release and antibacterial effect along the single sample examined in this study, which still had somewhat similar composition along the gradient, displays the strong structure-property relationship in Ag-based antibacterial coatings. The findings also demonstrate the possibility of tailoring the antibacterial effect of such coatings for specific therapeutic needs, simply by altering or mixing the structure of contributing Ag species. 


\section{Conclusions}

By applying a combinatorial approach, a continuous silver-titanium gradient coating was sputter deposited in a reactive $\left(\mathrm{O}_{2}\right)$ environment on a silicon wafer. The resulting sample was characterized and screened for antibacterial and potential bioactive properties related to structure and composition. While the sample was admittedly dominated by silver, several interesting findings related to structural properties were revealed that would be unlikely or more cumbersome to discover by manufacturing discrete samples. It was found that the silver-rich side reduced the viable count of $S$. aureus by $99,6 \%$ after 2 h exposure, whereas the count reduced on the titanium side was $17 \%$, compared to a negative control. This was correlated to $\mathrm{Ag}^{+}$release profiles, which showed a considerable burst release from the Ag-side compared to the much lower, linear release from the Ti-side. With the as-deposited compositional gradient ranging from 35 to $62 \mathrm{wt} \% \mathrm{Ag}$, i.e. a far smaller range than would constitute an approximate 10-fold difference in release, the resulting difference in antibacterial properties were contributed to structural variety of the Ag content. Clear in vitro apatite formation on both Ag- and Ti-sides also suggested that the coating had bioactive properties. With insight on the impact of structural variety, created by the combinatorial synthesis approach, future biomaterial coatings utilizing silver as an antibacterial agent may be tailored to better suit clinical needs.

\section{Acknowledgements}

This research was funded by the Swedish Foundation for Strategic Research (SSF), through the ProViking program. 


\section{References}

[1] Kennedy K, Stefansky T, Davy G, Zackay VF, Parker ER. Rapid Method for Determining Ternary-Alloy Phase Diagrams. J Appl Phys 1965;36:3808.

[2] Miller NC, Shirn GA. Co-Sputtered Au-SiO ${ }_{2}$ Cermet Films. Appl Phys Lett 1967;10:86.

[3] Lowe G. Combinatorial chemistry. Chem Soc Rev 1995;24:309.

[4] Thompson LA, Ellman JA. Synthesis and Applications of Small Molecule Libraries. Chem Rev 1996;96:555-600.

[5] Hook AL, Anderson DG, Langer R, Williams P, Davies MC, Alexander MR. High throughput methods applied in biomaterial development and discovery. Biomater 2010;31:187-98.

[6] Mei Y, Saha K, Bogatyrev SR, Yang J, Hook AL, Kalcioglu ZI, et al. Combinatorial development of biomaterials for clonal growth of human pluripotent stem cells. Nat Mater 2010;9:768-78.

[7] Gebhardt T, Music D, Takahashi T, Schneider JM. Combinatorial thin film materials science: From alloy discovery and optimization to alloy design. Thin Solid Films 2012;520:5491-9.

[8] Green ML, Takeuchi I, Hattrick-Simpers JR. Applications of high throughput (combinatorial) methodologies to electronic, magnetic, optical, and energy-related materials. J Appl Phys 2013;113:231101.

[9] Goodman SB, Yao Z, Keeney M, Yang F. The future of biologic coatings for orthopaedic implants. Biomater 2013;34:3174-83.

[10] Zhao L, Chu PK, Zhang Y, Wu Z. Antibacterial coatings on titanium implants. J Biomed Mater Res 2009;91B:470-80.

[11] Liu X, Chu PK, Ding C. Surface nano-functionalization of biomaterials. Mat Sci Eng R 2010;70:275-302.

[12] Liu X, Chu P, Ding C. Surface modification of titanium, titanium alloys, and related materials for biomedical applications. Mat Sci Eng R 2004;47:49-121.

[13] Feng QL, Wu J, Chen GQ, Cui FZ, Kim TN, Kim JO. A mechanistic study of the antibacterial effect of silver ions on Escherichia coli and Staphylococcus aureus. J Biomed Mater Res 2000;52:662-8.

[14] Bosetti M, Massè A, Tobin E, Cannas M. Silver coated materials for external fixation devices: in vitro biocompatibility and genotoxicity. Biomater 2002;23:887-92.

[15] Hardes J, Ahrens H, Gebert C, Streitbuerger A, Buerger H, Erren M, et al. Lack of toxicological side-effects in silver-coated megaprostheses in humans. Biomater 2007;28:2869-75.

[16] Zhao L, Wang H, Huo K, Cui L, Zhang W, Ni H, et al. Antibacterial nano-structured titania coating incorporated with silver nanoparticles. Biomater 2011;32:5706-16.

[17] Chen W, Liu Y, Courtney HS, Bettenga M, Agrawal CM, Bumgardner JD, et al. In vitro antibacterial and biological properties of magnetron co-sputtered silver-containing hydroxyapatite coating. Biomater 2006;27:5512-7.

[18] Noda I, Miyaji F, Ando Y, Miyamoto H, Shimazaki T, Yonekura Y, et al. Development of novel thermal sprayed antibacterial coating and evaluation of release properties of silver ions. J Biomed Mater Res 2009;89B:456-65.

[19] Necula BS, Fratila-Apachitei LE, Zaat SAJ, Apachitei I, Duszczyk J. In vitro antibacterial activity of porous $\mathrm{TiO}_{2}-\mathrm{Ag}$ composite layers against methicillin-resistant Staphylococcus aureus. Acta Biomater 2009;5:3573-80.

[20] Jamuna-Thevi K, Bakar SA, Ibrahim S, Shahab N, Toff MRM. Quantification of silver ion release, in vitro cytotoxicity and antibacterial properties of nanostuctured $\mathrm{Ag}$ doped $\mathrm{TiO}_{2}$ coatings on stainless steel deposited by RF magnetron sputtering. Vaccum 2011;86:235-41.

[21] Simchi A, Tamjid E, Pishbin F, Boccaccini AR. Recent progress in inorganic and composite coatings with bactericidal capability for orthopaedic applications. Nanomedicine: Nanotechnology, Biology and Medicine 2011;7:22-39.

[22] Campoccia D, Montanaro L, Arciola CR. A review of the biomaterials technologies for infectionresistant surfaces. Biomater 2013;34:8533-54.

[23] Noimark S, Dunnill CW, Wilson M, Parkin IP. The role of surfaces in catheter-associated infections. Chem Soc Rev 2009;38:3435.

[24] Hajipour MJ, Fromm KM, Ashkarran AA, Jimenez de Aberasturi D, de Larramendi IR, Rojo T, et al. Antibacterial properties of nanoparticles. Trends Biotechnol 2012;30:499-511.

[25] Unosson E, Tsekoura EK, Engqvist H, Welch K. Synergetic inactivation of Staphylococcus epidermidis and Streptococcus mutans in $\mathrm{TiO}_{2} / \mathrm{H}_{2} \mathrm{O}_{2} / \mathrm{UV}$ system. Biomatter 2013;3.

[26] An YH, Friedman RJ. Laboratory methods for studies of bacterial adhesion. Journal of Microbiological Methods 1997;30:141-52. 
[27] Lilja M, Forsgren J, Welch K, Åstrand M, Engqvist H, Strømme M. Photocatalytic and antimicrobial properties of surgical implant coatings of titanium dioxide deposited though cathodic arc evaporation. Biotechnol Lett 2012;34:2299-305.

[28] Forsgren J, Svahn F, Jarmar T, Engqvist H. Formation and adhesion of biomimetic hydroxyapatite deposited on titanium substrates. Acta Biomater 2007;3:980-4.

[29] Xia W, Lindahl C, Lausmaa J, Borchardt P, Ballo A, Thomsen P, et al. Biomineralized strontiumsubstituted apatite/titanium dioxide coating on titanium surfaces. Acta Biomater 2009;6:1591600.

[30] Chen C, Lee I-S, Zhang S-M, Yang HC. Acta Biomaterialia. Acta Biomater 2010;6:2274-81.

[31] Gristina AG. Biomaterial-centered infection: microbial adhesion versus tissue integration. Science 1987;237:1588-95.

[32] Campoccia D, Montanaro L, Arciola CR. A review of the clinical implications of anti-infective biomaterials and infection-resistant surfaces. Biomater 2013;34:8018-29.

[33] Neu HC. The crisis in antibiotic resistance. Science 1992;257:1064-73.

[34] Center for Disease Control. Antibiotic resistance threats in the United States. http://www.cdc.gov/drugresistance/threat-report-2013/; 2013.

[35] Puckett SD, Taylor E, Raimondo T, Webster TJ. The relationship between the nanostructure of titanium surfaces and bacterial attachment. Biomater 2010;31:706-13.

[36] Lan M-Y, Liu C-P, Huang H-H, Lee S-W. Both Enhanced Biocompatibility and Antibacterial Activity in Ag-Decorated $\mathrm{TiO}_{2}$ Nanotubes. PLoS ONE 2013;8:e75364.

[37] Uhm S-H, Song D-H, Kwon J-S, Lee S-B, Han J-G, Kim K-N. Tailoring of antibacterial Ag nanostructures on $\mathrm{TiO}_{2}$ nanotube layers by magnetron sputtering. J Biomed Mater Res 2013;102:592-603.

[38] Gao A, Hang R, Huang X, Zhao L, Zhang X, Wang L, et al. The effects of titania nanotubes with embedded silver oxide nanoparticles on bacteria and osteoblasts. Biomater 2014;35:4223-35.

[39] Xiang XD, Sun X, Briceño G, Lou Y, Wang KA, Chang H, et al. A combinatorial approach to materials discovery. Science 1995;268:1738-40.

[40] McFarland E, Weinberg W. Combinatorial approaches to materials discovery. Trends Biotechnol 1999; 17:107-15.

[41] Amis EJ, Xiang X-D, Zhao J-C. Combinatorial materials science: What's new since Edison? MRS Bulletin 2002;27:295-300.

[42] Takeuchi I, Lauterbach J, Fasolka MJ. Combinatorial materials synthesis. Materials Today 2005;8:18-26.

[43] Palmquist A, Omar OM, Esposito M, Lausmaa J, Thomsen P. Titanium oral implants: surface characteristics, interface biology and clinical outcome. J Roy Soc Interface 2010;7:S515-27.

[44] Sant SB, Gill KS, Burrell RE. Nanostructure, dissolution and morphology characteristics of microcidal silver films deposited by magnetron sputtering. Acta Biomater 2007;3:341-50.

[45] Unosson E, Welch K, Persson C, Engqvist H. Stability and prospect of $\mathrm{UV} / \mathrm{H}_{2} \mathrm{O}_{2}$ activated titania films for biomedical use. Appl Surf Sci 2013;285:317-23.

[46] Taylor PL, Omotoso O, Wiskel JB, Mitlin D, Burrell RE. Impact of heat on nanocrystalline silver dressings: Part II: Physical properties. Biomater 2005;26:7230-40.

[47] Carp O, Huisman C, Reller A. Photoinduced reactivity of titanium dioxide. Prog Solid State Ch 2004;32:33-177.

[48] Aita H, Hori N, Takeuchi M, Suzuki T, Yamada M, Anpo M, et al. The effect of ultraviolet functionalization of titanium on integration with bone. Biomater 2009;30:1015-25.

[49] Jimbo R, Ono D, Hirakawa Y, Odatsu T, Tanaka T, Sawase T. Accelerated Photo-Induced Hydrophilicity Promotes Osseointegration: An Animal Study. Clin Implant Dent Rel Res 2011;13:79-85.

[50] Page K, Palgrave RG, Parkin IP, Wilson M, Savin SLP, Chadwick AV. Titania and silver-titania composite films on glass-potent antimicrobial coatings. J Mater Chem 2006;17:95.

[51] Kumar R, Münstedt H. Silver ion release from antimicrobial polyamide/silver composites. Biomater 2005;26:2081-8.

[52] Welch K, Cai Y, Engqvist H, Strømme M. Dental adhesives with bioactive and on-demand bactericidal properties. Dent Mater 2010;26:491-9.

[53] Feng B, Chen J, Qi S, HE L, Zhao J, Zhang X. Characterization of surface oxide films on titanium and bioactivity. J Mater Sci: Mater Med 2002;13:457-64.

[54] Hollinger MA. Toxicological aspects of topical silver pharmaceuticals. Crit Rev Toxicol 1996;26:255-60.

[55] Lemire JA, Harrison JJ, Turner RJ. Antimicrobial activity of metals: mechanisms, molecular targets and applications. Nat Rev Microbiol 2013;11:371-84. 
[56] Mei S, Wang H, Wang W, Tong L, Pan H, Ruan C, et al. Antibacterial effects and biocompatibility of titanium surfaces with graded silver incorporation in titania nanotubes. Biomater 2014;35:4255-65. 
Table 1. Ion concentrations (mM) in blood plasma and Dulbeccos's PBS.

\begin{tabular}{lllllll}
\hline Ion & $\mathbf{N a}^{+}$ & $\mathbf{K}^{+}$ & $\mathbf{M g}^{2+}$ & $\mathbf{C a}^{2+}$ & $\mathbf{C l}^{-}$ & $\mathbf{H P O}_{4}{ }^{2-}$ \\
\hline Blood plasma & 142.0 & 5.0 & 1.5 & 2.5 & 103.0 & 1.0 \\
PBS & 145.0 & 4.2 & 0.49 & 0.91 & 143.0 & 9.6 \\
\hline
\end{tabular}

Figures

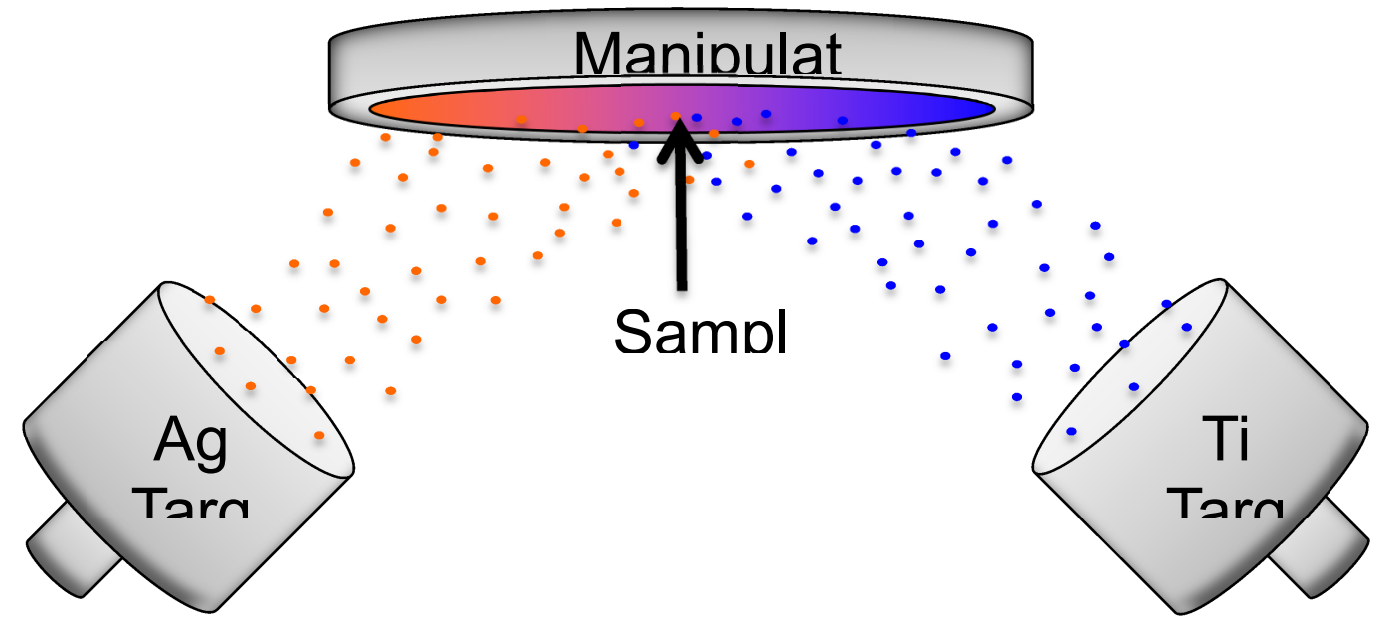

Fig. 1. Illustration showing arrangement of $\mathrm{Ag}$ and Ti deposition sources, and manipulator holding sample for binary, combinatorial sputtering.

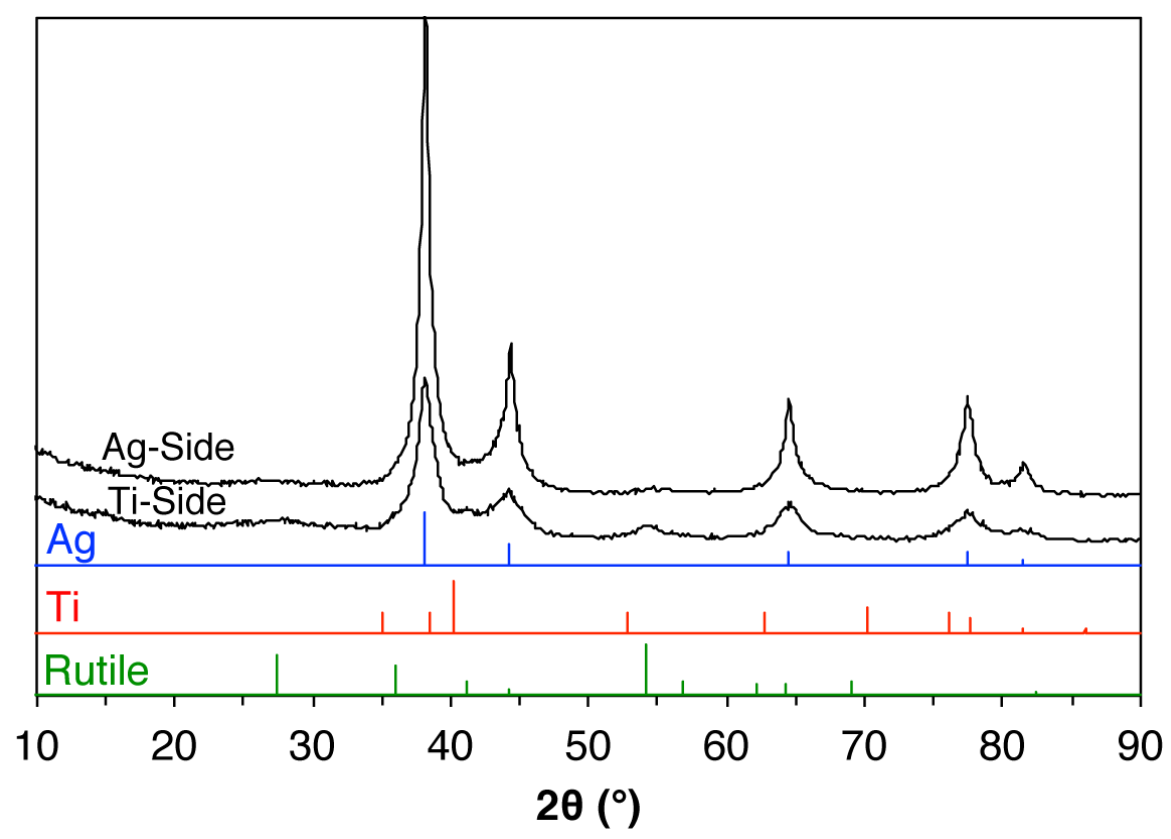

Fig. 2. GI-XRD spectrum from opposite ends of the deposited Ag-Ti oxide thin film. Reference patterns shown are: PDF 00-004-0783 (Ag), PDF 00-001-1197 (Ti) and PDF 00001-1292 (Rutile $\mathrm{TiO}_{2}$ ) 

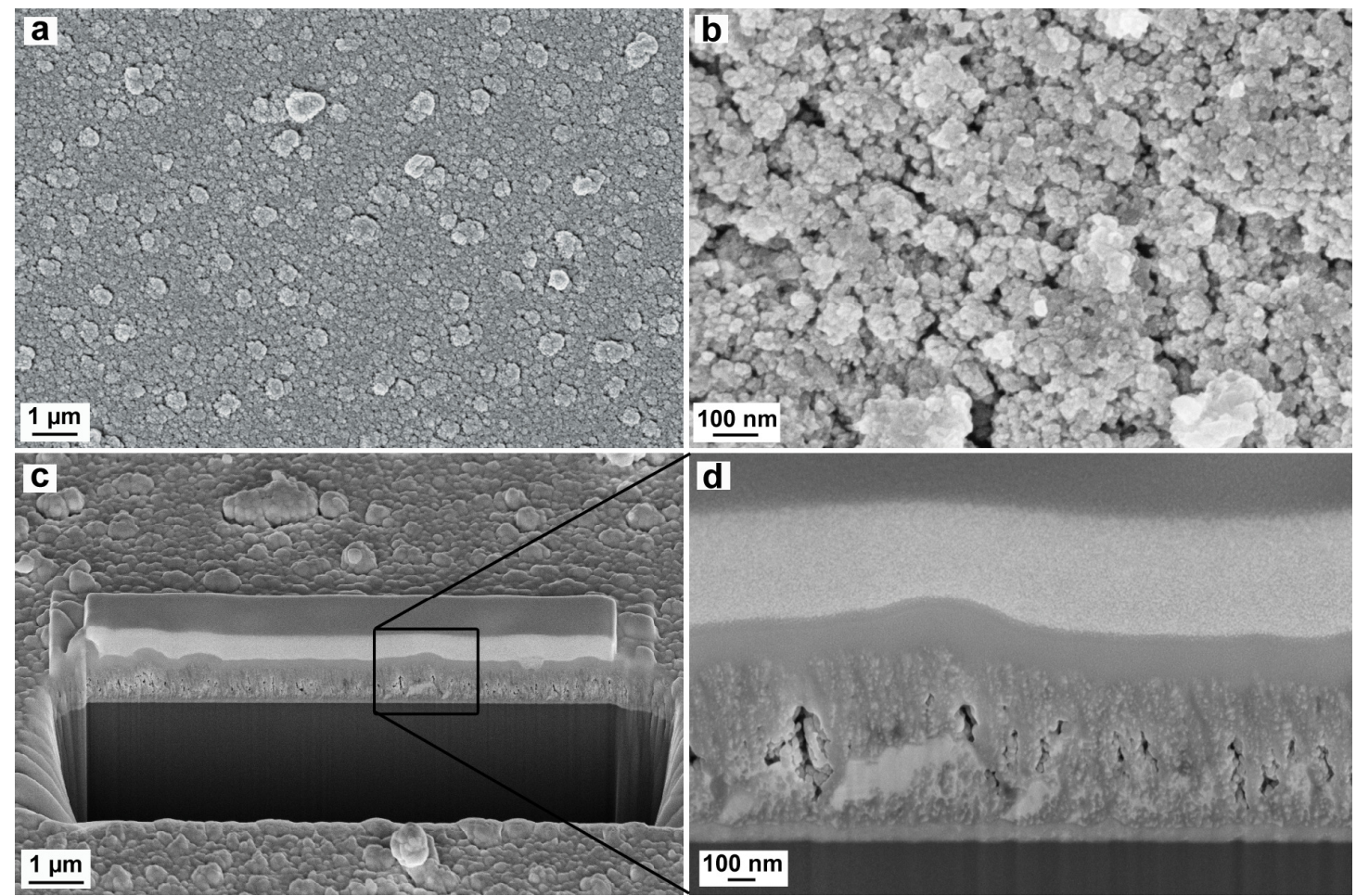

Fig. 3. SEM images of the Ag-side surface structure in (a) and (b). Images (c) and (d) showing FIB cut cross section of the Ag-side coating. In image (d), the depicted layers represent (from the bottom): Si wafer, Ag-Ti oxide coating (600 nm thick), and two layers of protective Pt film, deposited at different currents.
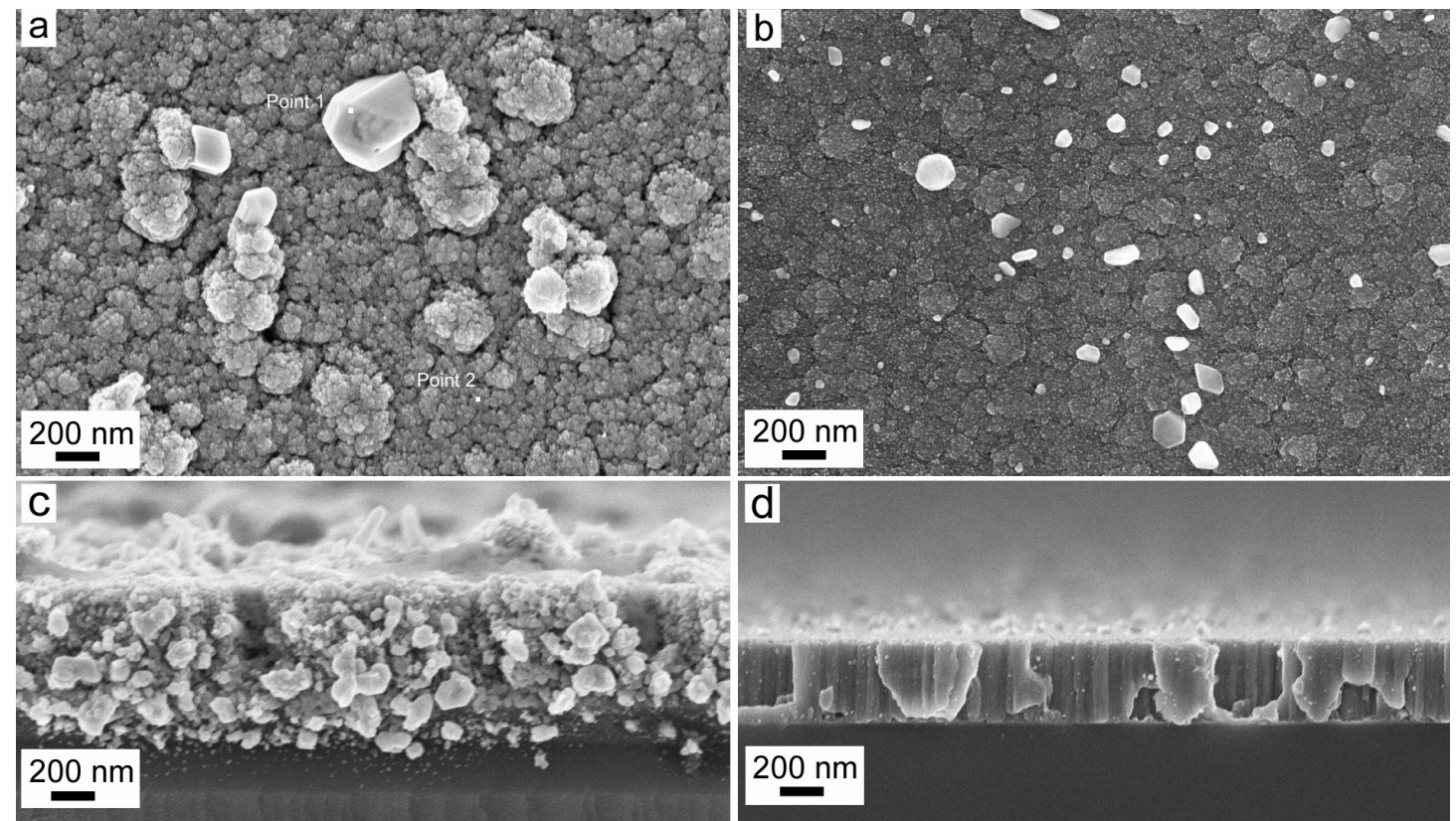

Fig. 4. SEM images of the center (a) and the Ti-side surface structure (b). Ag particles observed as brighter, crystalline objects in both images. EDS data from points 1 and 2 in (a) indicated Ag content of 99.9 and $47.8 \mathrm{wt} \%$, respectively. Cross-section of the coating at the center is shown in (c), and of the Ti-side in (d). 


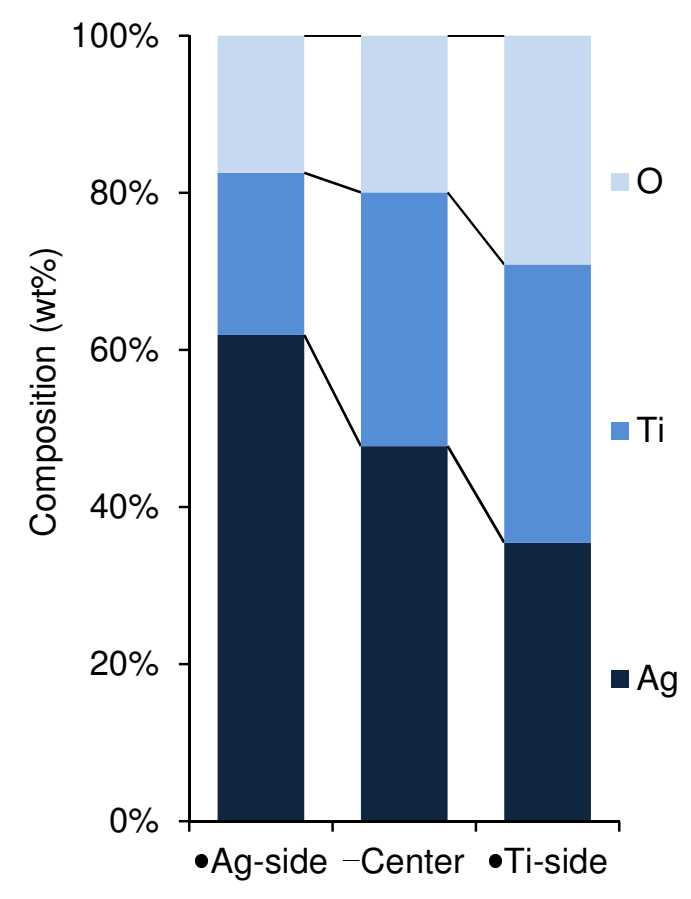

Fig. 5. EDS data obtained from Ag- and Ti-sides showing change in composition along the gradient (wt\%).

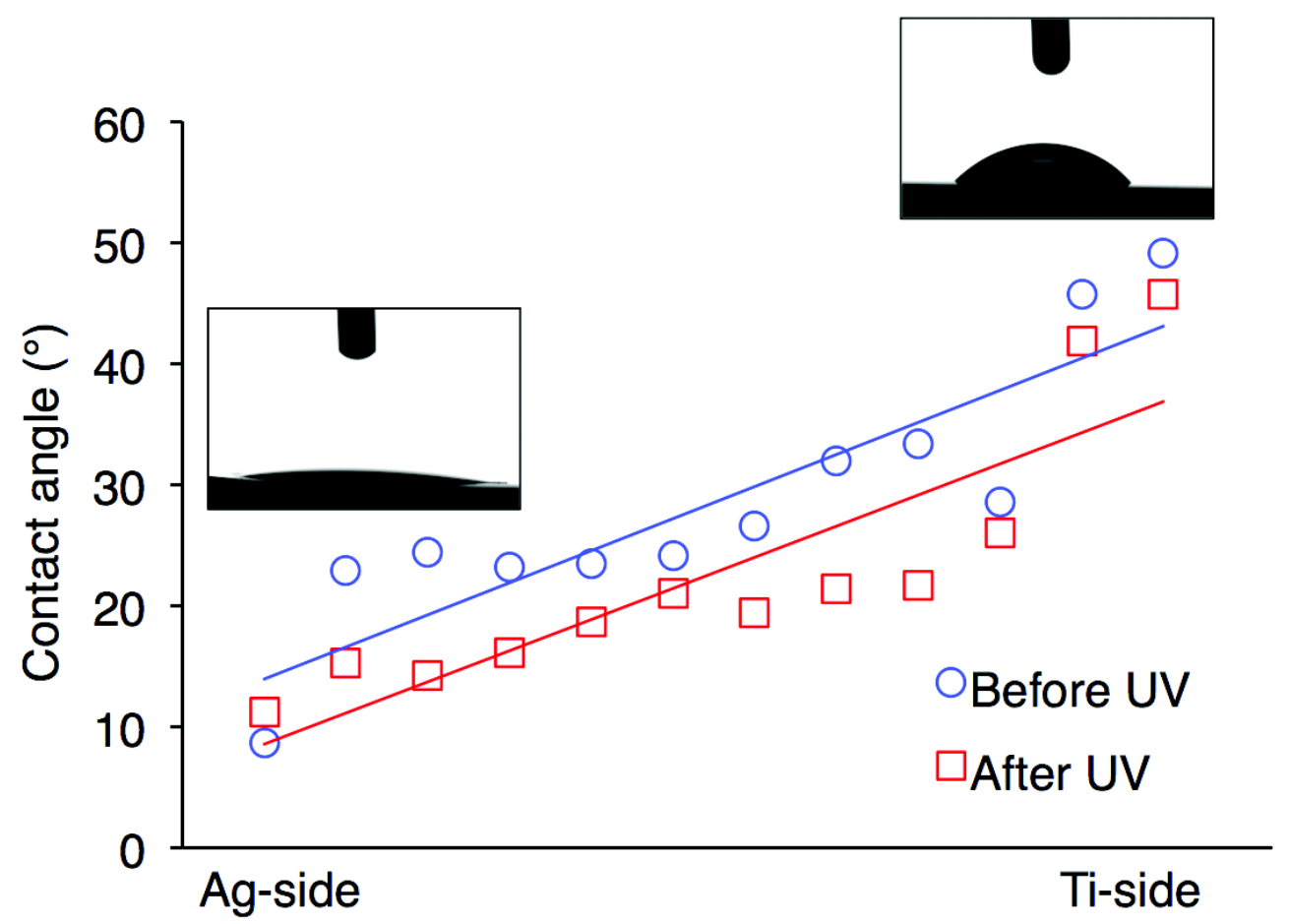

Fig. 6. Contact angle measurements along the $\mathrm{Ag}$-Ti oxide gradient, taken at $6 \mathrm{~mm}$ intervals. Trendlines are included for both series. 


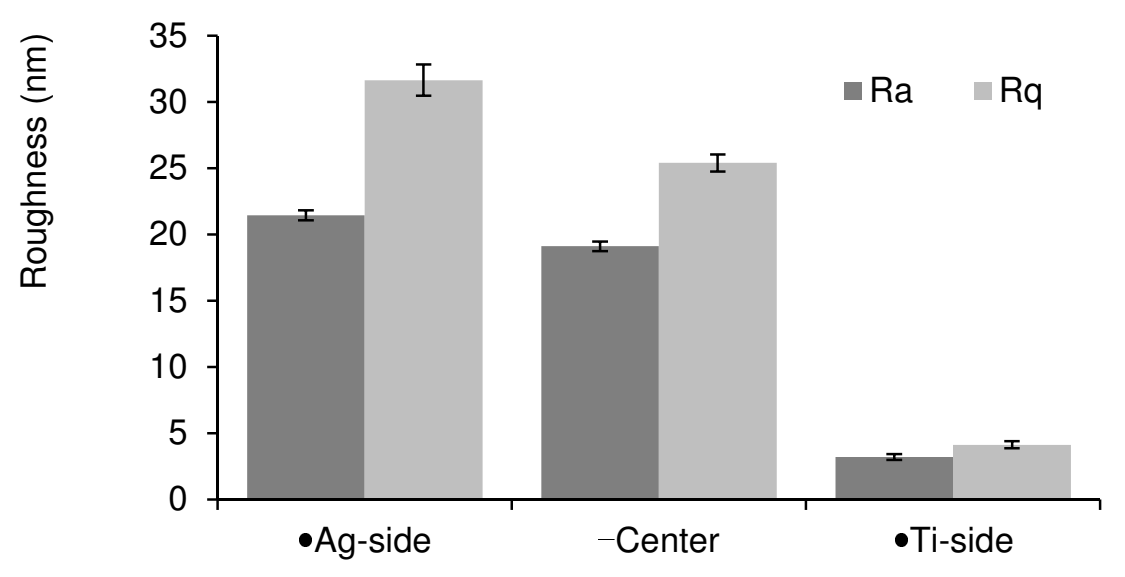

Fig. 7. Surface average roughness $\left(R_{a}\right)$ and surface root mean square roughness $\left(R_{q}\right)$ along the gradient coating.
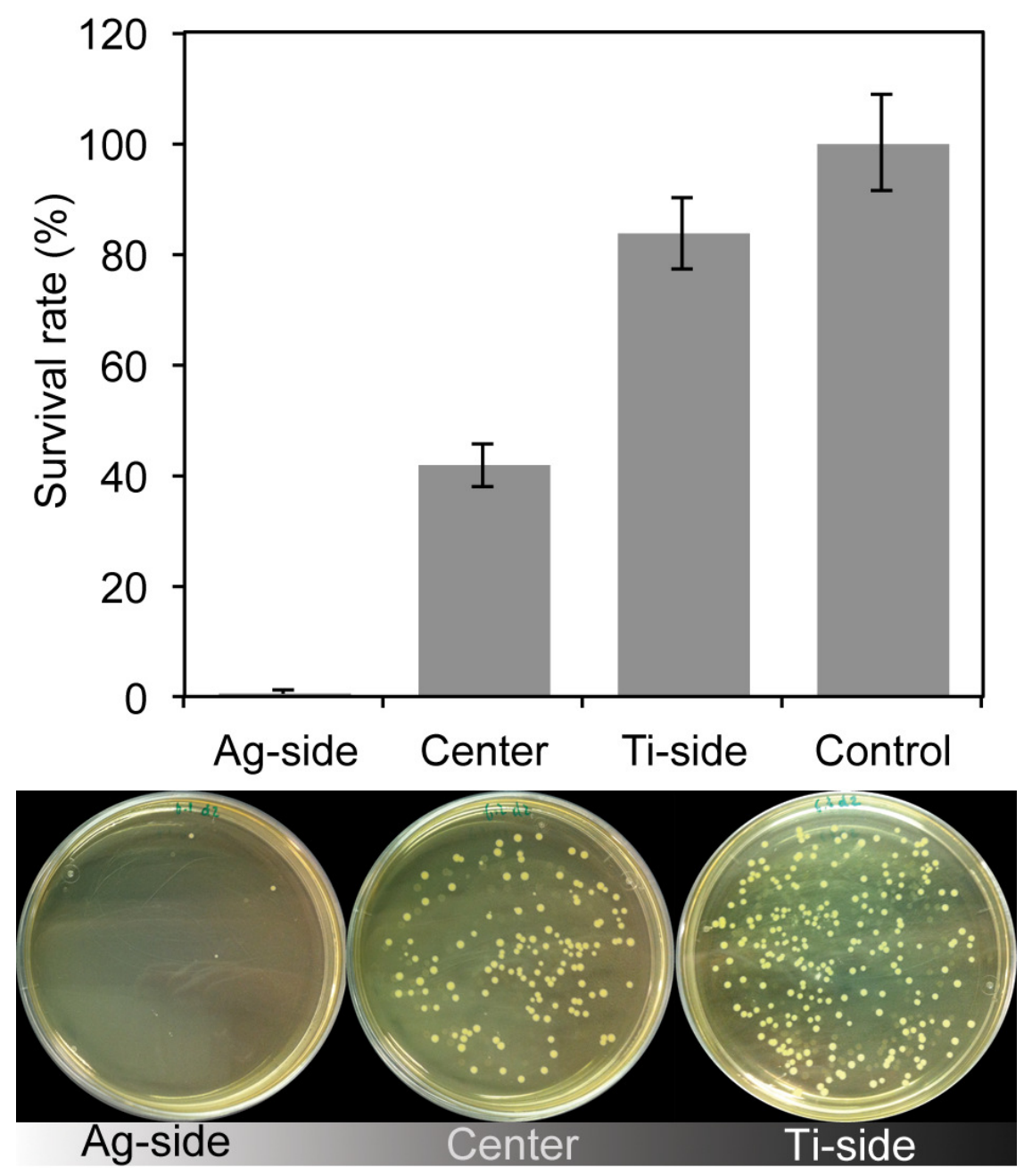

Fig. 8. Number of viable S. aureus colonies remaining after $2 \mathrm{~h}$ direct contact with Ag-side, center and Ti-side of the sample. 


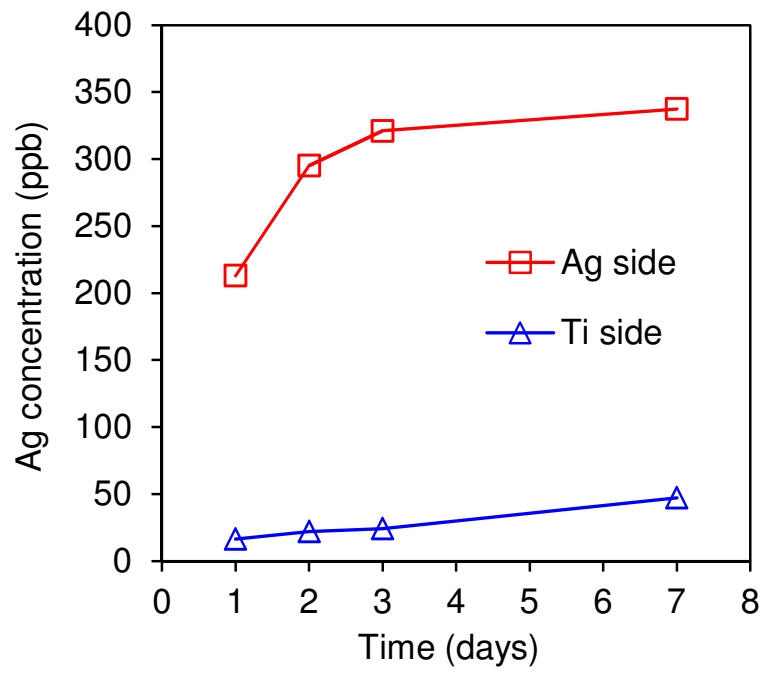

Fig. 9. Cumulative silver ion release profiles from Ag-and Ti-side samples in PBS.
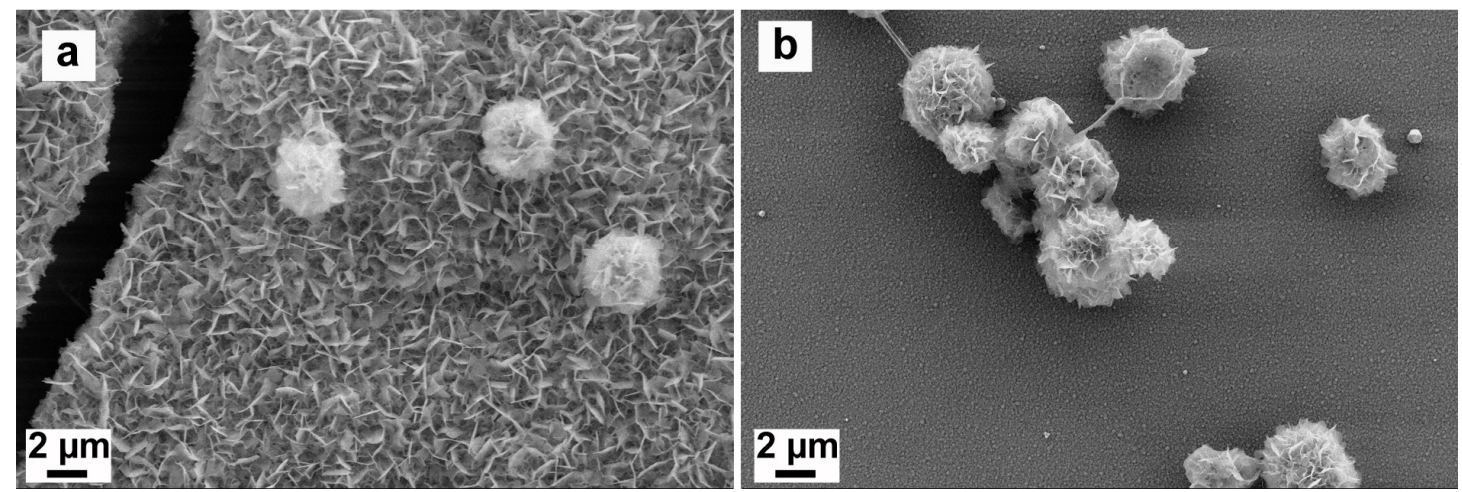

Fig. 10. SEM images of Ag-side (a) and Ti-side (b) samples after being submersed in PBS for 7 days, showing precipitated HA.

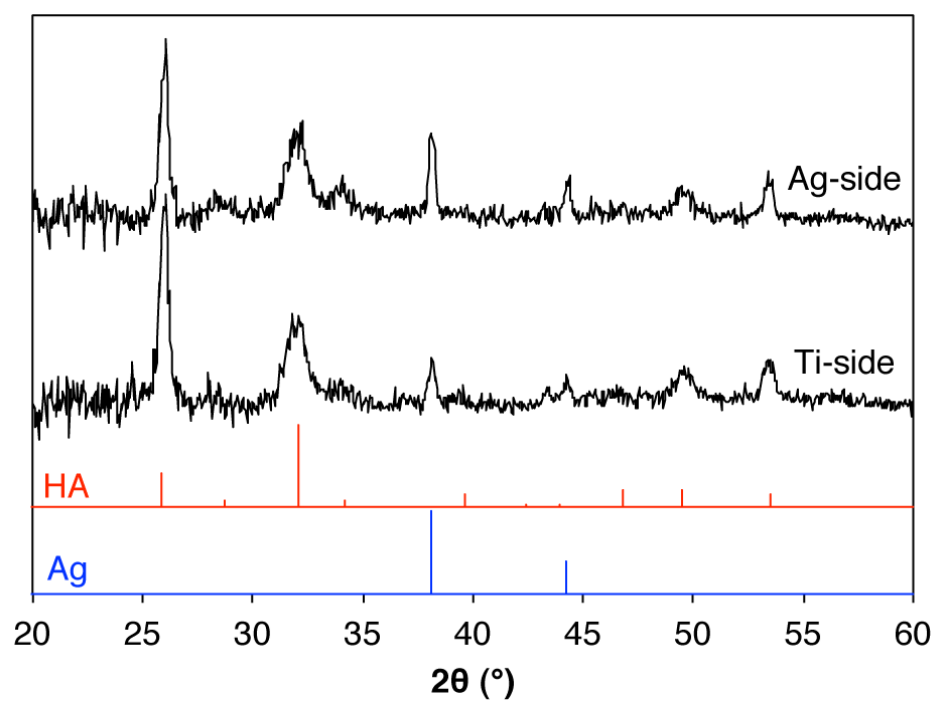

Fig. 11. GI-XRD of surface layer formed on samples after submersing them in PBS for 7 days. Reference patterns shown are: PDF 00-001-1008 (HA) and PDF 00-004-0783 (Ag). 

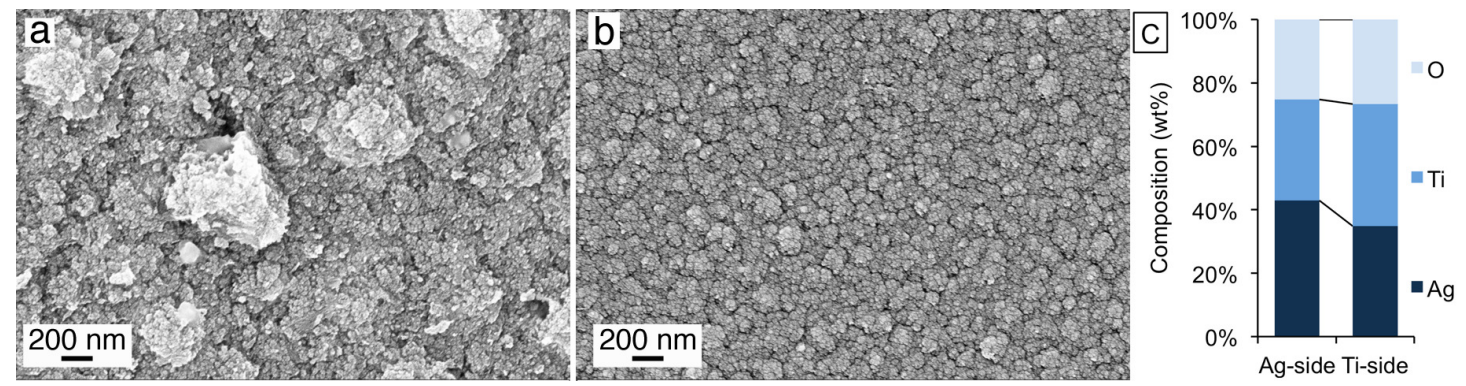

Fig. 12. SEM images of (a) Ag-side, (b) Ti-side, and (c) coating composition (EDS). Images and data taken after Ag-release study in PBS, with precipitated HA removed. 


\section{Graphical abstract}

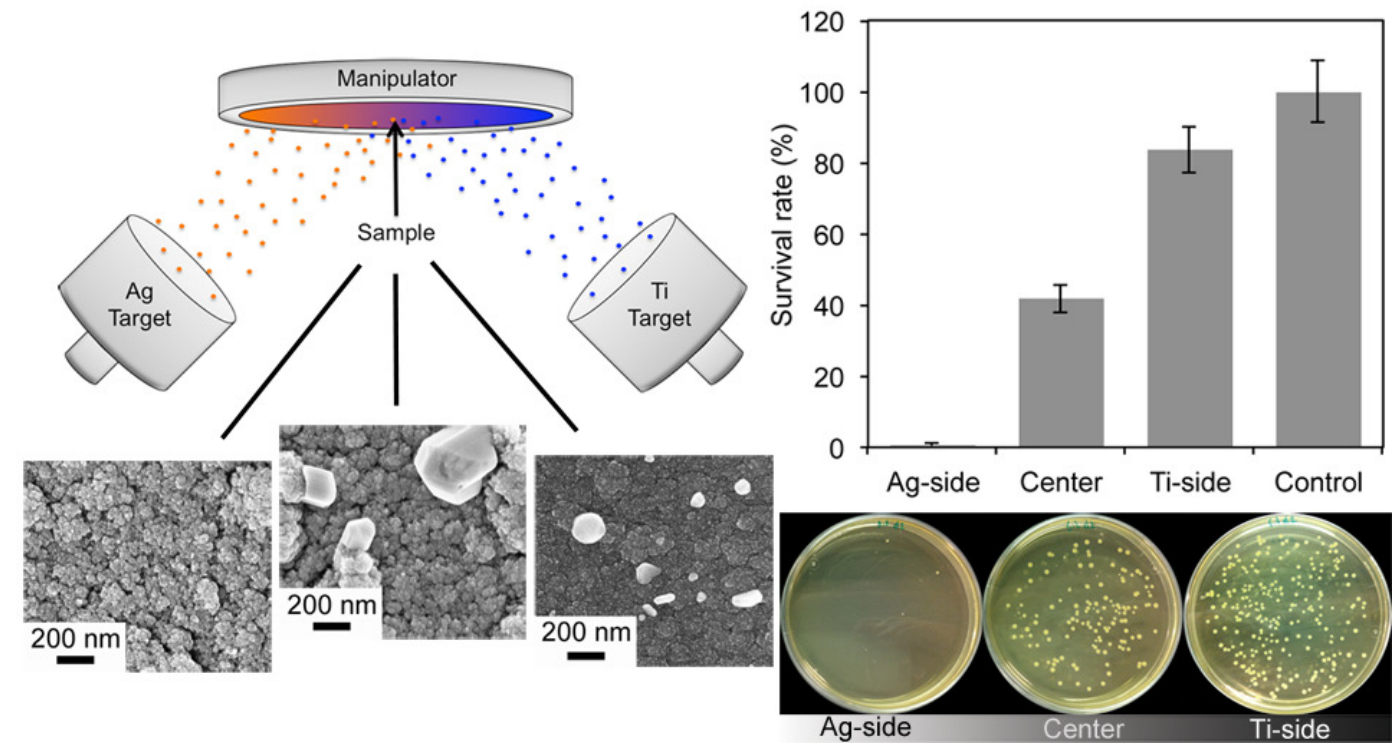

